\title{
Spectrums and Prognosis of Kidney Disease in Patients with Ankylosing Spondylitis
}

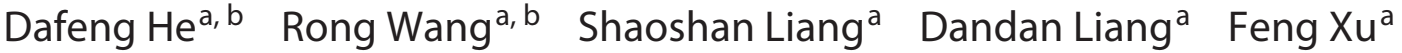 \\ Caihong Zeng ${ }^{\text {a }}$ Zheng Tang ${ }^{\mathrm{a}, \mathrm{c}}$
}

aNational Clinical Research Center of Kidney Disease, Jinling Medical College of Nanjing Medical University, Najing, China; bephrology Department, Northern Jiangsu People's Hospital Affiliated to Yangzhou University, Yangzhou, China; 'National Clinical Research Center of Kidney Disease, Jinling Medical College of Nanjing University, Najing, China

\section{Keywords}

Ankylosing spondylitis · Kidney · Pathological spectrums · $\lg$ A nephropathy · Prognosis

\begin{abstract}
Background/Aims: Renal involvement was a common extraarticular manifestation of ankylosing spondylitis (AS). Few reports have investigated the pathological characteristics and renal outcomes of AS patients with kidney disease. The aim of this study was to investigate the pathological spectrums and the renal prognosis of AS patients with kidney disease. Methods: This retrospective and observational study was conducted working on 62 patients ( 47 males and 15 females) with a diagnosis of AS (ACR, 1984) and renal biopsies between 2008 and 2017. The histopathological findings and associated clinical manifestations were collected, and the renal prognoses of patients with kidney disease were evaluated too. Multivariate binary logistic regression analysis was performed to identify risk factors for the occurrence of IgA nephropathy (IgAN). Results: Renal biopsy revealed that IgAN accounted for a majority (74.2\%) of the kidney disease with AS, while membranous nephropathies, minimal change disease, focal segmental glomerulosclero-
\end{abstract}

sis, and other lesions accounted for a small minority. Multivariate analysis revealed that serum immunoglobulin $A$ $>3.45 \mathrm{~g} / \mathrm{L}$ and immunoglobulin $\mathrm{G}>9.06 \mathrm{~g} / \mathrm{L}$ were risk factors for the occurrence of IgAN. With a median follow-up time of 24.3 months, 28 patients (50.9\%) reached complete remission, 9 patients (16.4\%) had partial remission, and 1 patient had an eGFR decline $>30 \%$. No difference was found in prognosis between IgAN and non-IgAN. Conclusion: IgAN occurred in $76.4 \%$ of the kidney disease with AS, and higher serum immunoglobulin $A$ and $G$ increased the risk for the occurrence of IgAN. The renal prognosis of kidney disease in AS was good.

\footnotetext{
(c) 2020 The Author(s)

Published by S. Karger AG, Basel
}

\section{Introduction}

Ankylosing spondylitis (AS) is the major subtype and a main outcome of an interrelated group of rheumatic diseases, which is named spondyloarthritis now [1]. Recent specialists believe AS is an advanced stage of axial spondyloarthritis, which can be identified by a combination of clinical symptoms and established radiographic changes $[2,3]$. Inflammatory back pain is the principal karger@karger.com www.karger.com/kdd

Karger $\stackrel{\text { ' }}{5}$

GOPEN ACCESS
(C) 2020 The Author(s)

Published by S. Karger AG, Basel

This article is licensed under the Creative Commons AttributionNonCommercial-NoDerivatives 4.0 International License (CC BYNC-ND) (http://www.karger.com/Services/OpenAccessLicense) Usage and distribution for commercial purposes as well as any distribution of modified material requires written permission.
Zheng Tang

National Clinical Research Center of Kidney Disease Jinling Medical College of Nanjing Medical University 305 East Zhong Shan Road, Nanjing 210002 (China) tang_dr@163.com 
clinical feature of AS, caused by sacroiliitis and inflammation at other locations, including the axial skeleton, peripheral arthritis, and extra-arthritis organs, for instance, anterior uveitis, heart, and kidney $[1,4]$. Renal complication accounted for $8.1-21.7 \%$ in extra-arthritis events $[2,5]$, it can lead to chronic or end-stage renal disease [6].

Recent studies investigated renal involvement in AS primarily according to urinary analysis. Clinicians observed that about $8.1-44.7 \%$ of AS patients were found abnormality in urinalysis, and microscopic hematuria was the most frequent finding in urinalysis for AS patients, but usually intermittent during follow-up, only in $10.5 \%$ patients were assumed glomerular hematuria [2, 7]. Therefore, abnormality in urinalysis has not always been the truth. Acknowledged, renal biopsy was the golden standard of diagnosis for the overwhelming majority of renal parenchyma disease, including nephropathy relevant to AS; meanwhile, it provided more information for physicians to choose an appropriate therapy plan and estimate the individual prognosis. However, considerably fewer reports have investigated the pathological characteristics and renal outcomes of AS patients with renal impairment. In addition, renal biopsy was performed in a handful of patients, while the observations were conflicting and controversial.

In the present study, we retrospectively analyzed 62 biopsy-proven kidney diseases with AS in our center. The aim of this study was to provide a description of the clinical features and histological spectrums of AS patients with renal involvement and to explore risk factors for the occurrence of IgA nephropathy (IgAN). The response to treatment and renal outcomes were also evaluated.

\section{Materials and Methods}

\section{Patients}

This is a retrospective and observational study that was performed at National Clinical Research Center of Kidney Diseases, Jinling Medical College of Nanjing Medical University (JMCNMU). A total of 275 hospitalized patients were diagnosed with AS in JMC-NMU from January 2008 to December 2017, according to the AS classification standard established by the American College of Rheumatology (ACR) in 1984, and 66 of them were hospitalized in the nephropathy department [8]. Renal biopsy was performed in patients with glomerular hematuria and/or proteinuria over $0.5 \mathrm{~g} /$ day and/or renal insufficiency. Sixty-two patients with renal biopsies were included. Demographic and clinical information was obtained through reviewing of medical records and laboratory tests. Renal histological examinations including light microscopy as well as immunofluorescence and follow-up data were thoroughly investigated.

Kidney Disease in Ankylosing Spondylitis

\section{Renal Histopathology}

The tissue for light microscopy was serially sectioned, using hematoxylin and eosin, periodic acid-Schiff, methenamine-silver, and Masson trichrome stains. Cryosections were stained with fluorescein isothiocyanate-conjugated rabbit anti-human immunoglobulin G (IgG), IgA, IgM, complement 3 (C3), and C1q. Paraffin sections stained fibrinogen. Tissue for electron microscopy was processed according to standard protocols. All biopsy slides were re-reviewed by 2 pathologists.

To explore the unique properties of immunoglobulin A nephropathy secondary to ankylosing spondylitis (IgAN-AS), the authors compared the pathologic characteristics of IgAN-AS with those of primary immunoglobulin A nephropathy (pIgAN) in the literature, such as PIgAN in the multicenter adult Chinese (MCAC) cohort conducted by Zeng et al. [9] and the pooled cohort by Barbour et al. [10]. Pathology findings of SIgAN-AS were defined according to the Oxford classification for pIgAN: M0/M1 as $\leq 50 \%$ of glomeruli with $<4$ mesangial cells/mesangial area or $>50 \%$ of glomeruli with $\geq 4$ mesangial cells/mesangial area; E0/E1 as the absence or presence of endocapillary hypercellularity; S0/S1 as the absence or presence of segmental sclerosis or tuft adhesions; T0/ $\mathrm{T} 1 / \mathrm{T} 2$ as the degree of tubular atrophy or interstitial fibrosis $(<25$, $25-50,>50 \%$, respectively) $[11,12]$. Crescent lesions were described as follows: C0 (no crescents), C1 (crescents in more than zero but less than one-fourth of glomeruli), and C2 (crescents in one-fourth or more of glomeruli) $[13,14]$.

\section{Treatment Protocol}

Patients were addressed in a flexible strategy after biopsy depending on clinical and pathological manifestations, mainly through immunosuppressants combined with small-dose oral glucocorticoids such as prednisone/methylprednisolone or not. Leflunomide was the most used immunosuppressant, followed by mycophenolate mofetil (MMF), cyclophosphamide (CTX), and tacrolimus. Oral glucocorticoids alone or aldosterone receptor antagonists (ARBs) or angiotensin-converting enzyme inhibitors (ACEIs) alone were employed in a small minority.

\section{Renal Outcomes}

The assessment of renal outcomes was based on the evolution of urinary proteinuria and estimated glomerular filtration rate (eGFR) during follow-up, and eGFR was calculated using the chronic kidney disease epidemiology collaboration (CKD-EPI) formula. The following outcomes were evaluated: (1) complete remission was identified as urinary protein $<0.4 \mathrm{~g} /$ day, and the eGFR decreased $<10 \%$. (2) Partial remission was defined as urinary protein decreased $>50 \%$ baseline and $<3.5 \mathrm{~g} /$ day, and the eGFR decreased $<10 \%$. (3) Treatment failure was defined as an increase in proteinuria, or a reduction in proteinuria but not to the extent of complete or partial remission. (4) ESRD was identified as an eGFR $<15 \mathrm{~mL} / \mathrm{min} / 1.73 \mathrm{~m}^{2}$, initiation of dialysis, or transplantation for over 3 months.

\section{Clinical and Laboratory Data}

The data included gender, age at onset and biopsy, duration, family history, renal involvement, extra-renal manifestations, blood pressure, 24-h urinary protein excretion, routine urinary analysis, blood test, and blood biochemical examination. IgG, IgA, IgM, C3, and C4 were likewise recorded. Renal function was estimated by assessing serum creatinine concentration and creati- 
Table 1. Demographic and clinical features of AS patients with kidney disease $(n=62)$

\begin{tabular}{|c|c|c|c|}
\hline Items & Values $(n=62)$ & Items & Values $(n=62)$ \\
\hline Male & $47(75.8)$ & Renal impairment & \\
\hline Age of AS onset, years & $30.2 \pm 10.6$ & Gross hematuria & $17(27.4)$ \\
\hline Age at renal biopsy, years & $35.1 \pm 10.7$ & Proteinuria and hematuria & $21(33.4)$ \\
\hline AS duration, months & $60.0(21.8-120)$ & Simple proteinuria & $8(12.9)$ \\
\hline Renal duration, months & $4.0(1.0-35.3)$ & Simple hematuria & $1(1.6)$ \\
\hline AS family history positivity & $8(12.9)$ & Nephrotic syndrome & $7(11.3)$ \\
\hline Renal family history positivity & $9(14.5)$ & Renal insufficiency & $11(17.7)$ \\
\hline Arthritis except AS family history & $8(12.9)$ & Chronic renal failure & $7(11.3)$ \\
\hline Onset order of nephropathy and arthritis & & Acute kidney injury & $5(8.1)$ \\
\hline Post-AS & $45(72.6)$ & Hypertension & $20(28.6)$ \\
\hline Concomitant with AS & $11(17.7)$ & Emerged hypertension & $14(22.6)$ \\
\hline Pre-AS & $6(9.7)$ & Edema & $15(24.2)$ \\
\hline Comorbidities & & Immunological features & \\
\hline Obesity & $4(6.5)$ & Antinuclear antibodies (+) & $9 / 62$ \\
\hline Diabetes mellitus & $3(4.8)$ & Anti-dsDNA (+) & $1 / 62$ \\
\hline Viral hepatitis & $3(4.8)$ & Anti-cardiolipin antibody $(+)$ & 4 \\
\hline Thyroid disorder & $3(4.8)$ & Anti-SSA and SSB & $1 / 42$ \\
\hline SLE & $2(3.2)$ & Anti-endothelial antibody & $4 / 5$ \\
\hline ANCA-associated vasculitis & $2(3.2)$ & Rheumatoid factor $(+)$ & $1 / 60$ \\
\hline Psoriasis & $1(1.6)$ & Low C3 & $8 / 62$ \\
\hline Uveitis & $2(3.2)$ & Low C4 & $1 / 62$ \\
\hline Ulcerative colitis & $1(1.6)$ & Hyper serum IgG & $8 / 62$ \\
\hline HLA-B27 positivity & $44 / 59$ & Hyper serum IgA & $20 / 62$ \\
\hline
\end{tabular}

Values are $n$ (\%) unless otherwise specified. AS, ankylosing spondylitis; C3, complement C3; C4, complement C4; IgG, immunoglobulin G; IgA, immunoglobulin A; SLE, systemic lupus erythematosus; ANCA, anti-neutrophil cytoplasmic antibodies; HLA-B27, human leukocyte antigen B27. Low C3 was defined as C3 <0.8 g/L; low C4 was defined as $\mathrm{C} 4<0.1 \mathrm{~g} / \mathrm{L}$; hyper serum IgG was defined as IgG $>16 \mathrm{~g} / \mathrm{L}$; hyper serum IgA was defined as IgA $>4 \mathrm{~g} / \mathrm{L}$. $(+)$ : positive, for example, antinuclear antibodies $(+)$ means antinuclear antibodies positive.

nine-based eGFR, using the CKD-EPI formula. Renal insufficiency was defined as an eGFR $<60 \mathrm{~mL} / \mathrm{min} / 1.73 \mathrm{~m}^{2}$, chronic kidney disease (CKD) was defined by the presence of a renal dysfunction for at least 3 months, and acute kidney injury (AKI) was defined as an eGFR decrease of $>25 \%$, known or presumed to have occurred within the prior 3-month period.

Hypertension was diagnosed according to the standards recommended by the World Health Organization Expert Committee. Proteinuria was defined as proteinuria $>0.4 \mathrm{~g} /$ day. Hematuria was defined as $>10 \times 10^{4} / \mathrm{mL}$. Macroscopic hematuria was defined as $>1,000 \times 10^{4} / \mathrm{mL}$ or visible to the eye. Nephrotic syndrome was defined as plasma albumin $<35 \mathrm{~g} / \mathrm{L}$ and proteinuria $>3.5 \mathrm{~g} /$ day. Hyper-IgG and hyper-IgA were defined as IgG $>16$ g/L and IgA $>4$ $\mathrm{g} / \mathrm{L}$. Low $\mathrm{C} 3$ was defined as serum $\mathrm{C} 3<0.8 \mathrm{~g} / \mathrm{L}$, low $\mathrm{C} 4$ was defined as serum $\mathrm{C} 4<0.1 \mathrm{~g} / \mathrm{L}$.

\section{Statistics}

All analyses were performed using SPSS 24.0 software for Windows (SPSS Inc., Chicago, IL, USA). Data were expressed as means $\pm \mathrm{SD}$ or median (interquartile ranges [IQRs]) for continuous variables and as number (percentage) for noncontinuous variables. The $\chi^{2}$ test or Fisher's test was used to assess categorical variables; for continuous variables, Student's $t$ test was used for those with characteristics of normality; and the nonparametric Mann-Whitney test was used for those without such characteristics. The multivariate binary logistic regression model was utilized to explore the risk factors for the occurrence of IgAN. The receiver operating characteristic (ROC) curve was drawn for variables to determine the optimal cutoff values to predict the occurrence of IgAN. All $p$ values were 2 -tailed, and values $<0.05$ were considered statistically significant.

\section{Results}

\section{General Conditions}

Forty-seven were male and 15 were female, and the mean age at AS onset and renal impairment was $30.2 \pm$ 10.6 and $35.1 \pm 10.7$ years, respectively. The median AS duration and renal duration were 60.0 months (IQR, 21.8-120.0 months) and 4.0 months (1.0-35.3 months), respectively. 8 patients $(12.9 \%)$ had an AS family history, another 8 patients $(12.9 \%)$ had a family history of arthri- 
Table 2. Histological findings of AS patients with kidney disease $(n=62)$

\begin{tabular}{lrl}
\hline Pathological type & $N$ & $\%$ \\
\hline IgAN & 46 & 74 \\
IgAN coexisted with other nephropathy & 2 & 3.2 \\
Idiopathic membranous nephropathy & 2 & 3.2 \\
Hypertensive nephropathy & 2 & 3.2 \\
Lupus nephropathy & 2 & 3.2 \\
MCD/FSGS & 3 & 4.8 \\
Proliferative glomerulonephritis & 1 & 1.6 \\
Amyloid A amyloidosis & 1 & 1.6 \\
Acute oxalate nephropathy & 1 & 1.6 \\
Glomerular minor lesion & 1 & 1.6 \\
Metabolic-related nephropathy & 1 & 1.6 \\
\hline
\end{tabular}

IgAN, IgA nephropathy; MCD/FSGS, minimal change disease or focal segmental glomerulosclerosis.

tis other than AS, and 9 patients (14.5\%) had a family history of kidney disease. There were $44 / 59$ (74.6\%) patients with positive HLA-B27 (Table 1).

\section{Clinical and Laboratory Characteristics at Biopsy}

As shown in Table 1, hypertension occurred in 20 patients $(28.6 \%)$, in which 14 did not have a history of hypertension. Edema occurred in 15 patients (24.2\%). Diagnosis of kidney disease was post-AS in most patients $(72.6 \%)$, concomitant with AS in $17.7 \%$, and pre-AS in 9.7\%. Among all patients, $17(27.4 \%)$ presented macroscopic hematuria, 21 (37.1\%) with asymptomatic proteinuria and microscopic hematuria, $8(12.9 \%)$ showed simple proteinuria, 7 (11.3\%) suffered from chronic renal failure (CRF), 5 patients (8.1\%) were suspected AKI, and 7 (11.3) showed nephrotic syndrome.

The excretion of urinary protein ranged from 0.10 to $19.39 \mathrm{~g} /$ day with an average of $2.38 \pm 3.26 \mathrm{~g} /$ day. Urinary protein $>1 \mathrm{~g} /$ day was seen in 23 patients $(37.1 \%)$, and urinary protein $>3.5 \mathrm{~g} /$ day was seen in 12 patients (19.4). Hematuria ranged from 0 to $4,750 \times 10^{4} / \mathrm{mL}$ with an average of $220 \pm 613 \times 10^{4} / \mathrm{mL}$. The serum levels of creatinine and UA were $1.09 \pm 0.93 \mathrm{mg} / \mathrm{dL}$ and $354 \pm 94 \mu \mathrm{mol} / \mathrm{L}$. The mean eGFR was $100.49 \pm 34.06 \mathrm{~mL} / \mathrm{min} / \mathrm{m}^{2}$. Approximately one-third of cases showed hyper-IgA with an average of $3.59 \pm 1.27 \mathrm{~g} / \mathrm{L}$, and $12.9 \%$ of the cases presented with hyper-IgG with an average of $11.95 \pm 3.91 \mathrm{~g} / \mathrm{L}$.

Autoantibodies were detected positive in several cases. ANA was found positive in 9/62 patients, anti-dsDNA was positive in $1 / 62$ patient, and 2 patients were diagnosed with systemic lupus erythematosus (SLE), but the others were not. Moreover, 2 patients with serum antineutrophil cytoplasmic antibodies positive (ANCA+) were suspected as ANCA-associated systematic vasculitis (AAV). Several of them had comorbidities, such as obesity, diabetes mellitus, thyroid disorders, uveitis, and ulcerative colitis (Table 1).

\section{Histopathological Findings}

The pathological spectrums are shown in Table 2. IgAN accounted for a majority (74.2\%) of the pathological types. Furthermore, 2 patients were proven to be IgAN combined with other glomerulonephritis (one with ANCA positive and the other with acute poststreptococcal glomerulonephritis), whereas membranous nephropathies $(\mathrm{MN})(2,3.2 \%)$, minimal change disease (MCD), focal segmental glomerulosclerosis (FSGS), hypertensive nephropathy, AAV, and so on accounted for a small minority. In patients with $\mathrm{MN}$, phospholipase A2 receptor was identified in their serum, and IgG4 was the predominant IgG subclass for them, as demonstrated by immunofluorescence staining. Additionally, the 6 patients with nephrotic syndrome did not belong to the IgAN subpopulation, but proven to be $2 \mathrm{MNs}$, 2 lupus nephropathies, 1 amyloid $\mathrm{A}$ amyloidosis, and 1 proliferative glomerulonephritis with trace IgA. Interestingly, with regard to $20 \mathrm{pa}-$ tients with serum hyper-immunoglobulin A, IgAN accounted for $90 \%$, and idiopathic membranous nephropathy and acute oxalate nephropathy each accounted for $5 \%$.

\section{Risk Factors for the Occurrence of IgAN in Patients with AS}

The clinical characteristics were compared between patients with IgAN (IgAN-AS) and patients with nonIgAN (non-IgAN-AS). Univariate analysis such as the $\chi^{2}$ test or Fisher's test or Student's $t$ test was performed. Age, systolic pressure, edema, AKI, asymptomatic proteinuria and hematuria, nephrotic syndrome, urinary proteinuria, serum creatinine, eGFR, cystatin C, albumin, globulin, IgA, and IgG differed significantly between the 2 groups (Table 3). The different features of IgAN-AS and nonIgAN-AS are not the focus of this study and will not be described in this paper.

Then, these parameters with $p<0.05$ in the univariate analysis and macroscopic hematuria were considered in the multivariate binary logistic regression model. The ROC curve was drawn to determine the optimal cutoff values to predict the occurrence of IgAN. As shown in Table 4, IgA $>3.45 \mathrm{~g} / \mathrm{L}$ (hazard rate [HR] 21.367, $p=$ $0.013)$ and $\operatorname{IgG}>9.06 \mathrm{~g} / \mathrm{L}$ (HR 27.461, $p=0.003$ ) were independent risk factors for the occurrence of IgAN, while 
Table 3. Comparison of characteristics between patients with IgAN and patients with non-IgAN

\begin{tabular}{|c|c|c|c|}
\hline & $\begin{array}{l}\operatorname{IgAN} \\
(n=46)\end{array}$ & $\begin{array}{l}\text { Non-IgAN } \\
(n=16)\end{array}$ & $p$ value \\
\hline \multicolumn{4}{|l|}{ Demographic characteristics } \\
\hline Age, years & $33.4 \pm 10.0$ & $40.3 \pm 11.3$ & 0.02 \\
\hline Age at onset of kidney disease, years & $33.3 \pm 10.0$ & $40.1 \pm 11.2$ & 0.03 \\
\hline AS duration, months & $50.5(21.8-120)$ & $120(15.0-128)$ & 0.27 \\
\hline Renal duration, months & $6.5(1.0-36.0)$ & $2.0(0.85-10.5)$ & 0.17 \\
\hline Systolic pressure, $\mathrm{mm} \mathrm{Hg}$ & $126 \pm 15.7$ & $136 \pm 16.2$ & 0.045 \\
\hline AS family history positivity & $8(17.4)$ & 0 & 0.10 \\
\hline Renal history positivity & $7(15.2)$ & $2(12.5)$ & $>0.99$ \\
\hline \multicolumn{4}{|l|}{ Clinical manifestations } \\
\hline Macroscopic hematuria & $15(32.6)$ & $2(12.5)$ & 0.19 \\
\hline Edema & $6(13)$ & $9(56.3)$ & 0.001 \\
\hline Acute kidney injury & $1(2.2)$ & $4(25)$ & 0.01 \\
\hline Chronic renal failure & $5(10.9)$ & $2(12.5)$ & $>0.99$ \\
\hline Asymptomatic proteinuria and hematuria & $22(47.8)$ & $1(6.3)$ & 0.006 \\
\hline Nephrotic syndrome & 0 & $6(37.5)$ & 0.001 \\
\hline \multicolumn{4}{|l|}{ Laboratory examination } \\
\hline Urinary protein, g/day & $1.326 \pm 0.974$ & $4.443 \pm 5.201$ & $<0.001$ \\
\hline $\mathrm{eGFR}, \mathrm{mL} / \mathrm{min} / 1.73 \mathrm{~m}^{2}$ & $108.0 \pm 28.1$ & $78.9 \pm 41.0$ & 0.003 \\
\hline Serum creatinine, $\mathrm{mg} / \mathrm{dL}$ & $0.884 \pm 0.332$ & $1.694 \pm 1.637$ & 0.002 \\
\hline Cystatin $\mathrm{C}, \mathrm{mg} / \mathrm{dL}$ & $1.055 \pm 0.346$ & $1.501 \pm 0.793$ & 0.003 \\
\hline Albumin, $\mathrm{g} / \mathrm{L}$ & $42.0 \pm 4.7$ & $36.9 \pm 8.9$ & 0.005 \\
\hline Uric acid & $343 \pm 87.2$ & $384 \pm 107$ & 0.133 \\
\hline Hyperuricemia & $6(37.5)$ & $9(19.6)$ & 0.149 \\
\hline Globulin, g/L & $28.3 \pm 6.0$ & $23.4 \pm 4.4$ & 0.004 \\
\hline Serum IgA, g/L & $3.769 \pm 1.318$ & $3.071 \pm 1.003$ & 0.06 \\
\hline $\operatorname{IgA}>3.45 \mathrm{~g} / \mathrm{L}$ & $28(62.2)$ & $3(18.8)$ & 0.004 \\
\hline Serum IgG, g/L & $12.82 \pm 3.489$ & $9.465 \pm 4.085$ & 0.002 \\
\hline IgG $>9.06 \mathrm{~g} / \mathrm{L}$ & $43(93.5)$ & $7(43.8)$ & $<0.001$ \\
\hline HLA-B27 positivity & $35(76.1)$ & $9(69.2)$ & 0.51 \\
\hline \multicolumn{4}{|c|}{$\begin{array}{l}\text { Values are } n(\%) \text { unless otherwise specified. Receiver operating characteristic curve was drawn for variable } \\
\text { to determine the optimal cutoff values to predict the occurrence of IgAN. Hyperuricemia was defined as } 7 \mathrm{mg} \\
\mathrm{dL}(417 \mu \mathrm{mol} / \mathrm{L}) \text { in men and above } 6 \mathrm{mg} / \mathrm{dL}(357 \mu \mathrm{mol} / \mathrm{L}) \text { in women. IgAN, IgA nephropathy; IgA, immunoglobulir } \\
\text { A; IgG, immunoglobulin G; AS, ankylosing spondylitis; eGFR, estimated glomerular filtration rates; HLA-B27 } \\
\text { human leukocyte antigen B27. }\end{array}$} \\
\hline
\end{tabular}

Table 4. Risk factors for the occurrence of IgAN

\begin{tabular}{lrll}
\hline Items & HR & $95 \%$ CI & $p$ value \\
\hline Edema & 0.041 & $0.004-0.445$ & 0.009 \\
Systolic pressure & 0.933 & $0.873-0.997$ & 0.04 \\
Serum IgA $>3.45 \mathrm{~g} / \mathrm{L}$ & 21.367 & $1.896-240.775$ & 0.013 \\
Serum IgG $>9.06 \mathrm{~g} / \mathrm{L}$ & 27.461 & $2.994-251.867$ & 0.003 \\
\hline
\end{tabular}

Parameters with $p<0.05$ and macroscopic hematuria were considered in multivariate binary logistic regression analysis. The receiver operating characteristic curve was used to determine the optimal cutoff values to predict the occurrence of $\operatorname{IgAN}$. IgA, immunoglobulin A; IgG, immunoglobulin G.
Table 5. Renal outcomes of IgAN-AS patients $(n=44)$ and nonIgAN-AS patients $(n=11)$

\begin{tabular}{|c|c|c|c|}
\hline & $\begin{array}{l}\text { Total } \\
(n=55)\end{array}$ & $\begin{array}{l}\text { IgAN } \\
\text { patients } \\
(n=44)\end{array}$ & $\begin{array}{l}\text { Non-IgAN } \\
\text { patients } \\
(n=11)\end{array}$ \\
\hline \multicolumn{4}{|c|}{ Remission of urinary protein } \\
\hline Complete remission & $28(50.9)$ & $23(52.3)$ & $5(45.5)$ \\
\hline Partial remission & $9(16.4)$ & $7(15.9)$ & $2(18.2)$ \\
\hline Invalid & $17(30.9)$ & $14(31.8)$ & $3(27.3)$ \\
\hline eGFR decline $>30 \%$ & $1(1.8)$ & $1(2.3)$ & 0 \\
\hline CRF present & $4(7.3)$ & $2(4.5)$ & $2(18.2)$ \\
\hline
\end{tabular}

Values are $n$ (\%) unless otherwise specified. eGFR, estimated glomerular filtration rates; CRF, chronic renal failure. 
Table 6. Comparison of pathological features of IgAN-AS and pIgAN in the literature

\begin{tabular}{lcll}
\hline & $\begin{array}{l}\text { IgAN-AS } \\
(n=46)\end{array}$ & $\begin{array}{l}\text { pIgAN, multicenter } \\
\text { adult Chinese cohort } \\
(n=1,026)\end{array}$ & $\begin{array}{l}\text { pIgAN, pooled } \\
\text { cohort } \\
(n=901)\end{array}$ \\
\hline M1 & $19(41.3)$ & $441(43)$ & $383(42.5)$ \\
E1 & $3(6.5)$ & $113(11)^{*}$ & $163(18.1)^{*}$ \\
S1 & $31(67.4)$ & $852(83)^{*}$ & $676(75)$ \\
T1-2 & $9(19.6)$ & $280(27.3)$ & $199(22.1)$ \\
Necrosis & $5(10.9)$ & $154(15)$ & - \\
C1-2 & $20(43.5)$ & $493(48.1)$ & $154(17.1)^{*}$ \\
\hline
\end{tabular}

Pathology findings are defined according to Oxford classification: $\mathrm{C} 1$ in $<25 \%$ and $\mathrm{C} 2$ in $\geq 25 \%$ of glomeruli. Data presented as number (percentage) unless stated otherwise. IgANAS, immunoglobulin A nephropathy secondary to ankylosing spondylitis; pIgAN, primary immunoglobulin A nephropathy. * A statistical difference between pIgAN and IgAN-AS.

edema was not usually associated with IgAN (HR 0.041, $p=0.009)$. Systolic pressure was found statistically significant in this multivariate binary logistic regression model, but its HR was close to 1 , indicating an ambiguous predictive efficiency.

\section{Renal Outcome Data of AS Patients with Kidney \\ Disease}

As shown in online suppl. Table 1 (for all online suppl. material, see www.karger.com/doi/10.1159/000509248), $\mathrm{ARB} / \mathrm{ACEI}$ was the most used drug, nearly one-half of the patients were treated with oral glucocorticoid, 27 patients (43.5\%) were administered immunosuppressants, and 17 patients took immunosuppressants combined with oral glucocorticoids. Leflunomide and tacrolimus were more frequently used in patients with IgAN than in patients with non-IgAN.

Fifty-two patients were followed up $>1$ month, with a median follow-up of 24.3 months (IQR, 12.4-56.1 months). Renal outcomes performed well, involved both clinical remission and eGFR decline. The probabilities of complete remission and partial remission were 50.9 and $16.4 \%$. No patients met ESRD or initiated dialysis, and eGFR declined beyond $50 \%$ baseline level was not seen in our cohort. One patient with IgAN had an eGFR decline $>30 \%$ (Table 5).

\section{Comparison of Pathological Characteristics between} IgAN-AS and PIgAN

We had described the clinicopathologic characteristics of IgAN-AS in another paper [8]; here we compared the pathological features of IgAN-AS with those of pIgAN in the literature to explore the unique properties of IgANAS. As shown in Table 6, a few different pathological characteristics were found between IgAN-AS and pIgAN. The E1, S1, T1-2, and necrosis lesions were less frequent in IgAN-AS than those in pIgAN in the multicenter adult Chinese cohort and the pooled cohort by Cattran et al. [11]. Significant differences were found in the E1 lesion between patients with IgAN-AS and those with pIgAN in both the MCAC cohort and the pooled cohort. S1 lesions differed statistically between IgAN-AS and pIgAN in the MCAC cohort, but the difference of S1 lesions between IgAN-AS and pIgAN in the pooled cohort did not reach statistical significance. In addition, crescent lesions differed significantly between IgAN-AS and pIgAN in the pooled cohort.

\section{Discussion/Conclusion}

Although previous studies reported renal involvement related to AS occurred at rates from 8.1 to $44.7 \%$, most of them were accessed by urinary analysis and fewer researches included biopsy data in a small part of populations $[2,5]$. The present study, which is the largest series of biopsy-proven AS-related nephropathies published to date, focused on the clinical and pathological presentation of this complication. Additionally, prognosis of IgAN-AS was analyzed.

The clinical characteristics of the patients accessed in this study did not differ from the previous literature. Most patients were male and young adults. Positivity for HLAB27 was $74.6 \%$. Renal involvement varied from simple hematuria or proteinuria to renal insufficiency. Hematuria was the most common manifestation. However, most cases accompanied with proteinuria in our cohort, and only 1 case presented with simple hematuria, which differed from previous studies. Wu et al. [5] reported that renal abnormality occurred in $22.4 \%$ of AS patients, hematuria in $14.3 \%$ cases, and proteinuria in $4.9 \%$ cases. Nephrotic syndrome was rare in patients with AS, and the most reported type was amyloidosis [15]. In this study, approximately one-tenth patients presented with nephrotic syndrome, as it turned out $2 \mathrm{MNs}, 2$ lupus nephritises, 1 amyloid A amyloidosis, and 1 proliferative glomerulonephritis with trace IgA. The $2 \mathrm{MNs}$ in our cohort were stained anti-PLA2R antibody-positive and IgG4 was the predominant IgG subclass, indicating an idiopathic origin. Few patients had AS combined with other systematic diseases such as SLE and AAV. Concerning the com- 
plication of AAV, Hara et al. [16] reported 1 female AS patients with weakly positive perinuclear anti-neutrophil cytoplasmic antibodies, who suffered from diffuse alveolar hemorrhage but not renal damage. Moreover, one study observed that the presence of pANCA was significantly increased in AS patients who also have ulcerative colitis and needed to perform endoscopy [17].

This study provided important insights into the renal involvement during AS, and renal damage could occur at any stage of AS. Kidney disease came to light after arthritis in most patients, and concomitant with AS in $17.7 \%$ patients. Moreover, kidney disease preceded arthritis in 9.7\% patients. This phenomenon was in accordance with the previous study conducted by Li et al. [18]. However, chronic inflammation perhaps affected the sacroiliac joints and entheses of axial spine unconsciously for a long time.

Renal biopsy was the gold standard for definitive diagnosis of renal parenchyma disease, including nephropathy associated with AS. Our study provided the largest series of biopsy-proven renal involvement in AS so far. One of our most important discoveries was that IgAN dominated the histological types, which was in accordance with previous studies [5, 7], but the incidence rate of IgAN was much higher than that in the preceding studies. Interestingly, 18 of the 20 patients with hyper-IgA proved to be IgAN, and IgAN was not regarded in the 6 patients with nephrotic syndrome. $27.4 \%$ patients presented with macroscopic hematuria, and $88.2 \%$ of them showed characteristics of IgAN. Multivariate binary logistic regression revealed that serum $\operatorname{IgA}>3.45 \mathrm{~g} / \mathrm{L}$ and $\operatorname{IgG}>9.06 \mathrm{~g} / \mathrm{L}$ were risk factors for the occurrence of IgAN.

AS and IgAN shared some immunological features, for example, elevated serum IgA and IgA-immune complex levels. Abnormalities in IgA serum levels in AS patients were initially described in the 1970s, and the elevated IgA was mainly IgA1 subtype [19, 20]. Hyper-IgA levels were presented in $37 \%$ IgAN-AS patients in our cohort. On the one hand, investigators observed about $46.2-58.8 \%$ of patients with AS and psoriatic arthritis presented some degree of subclinical gut inflammation demonstrated by ileocolonoscopy $[21,22]$. Bacterial antigen could attack intestinal mucosa due to the increased intestinal permeability [23] and then evoke an immune response in AS patients, overproducing IgA antibodies to protect intestinal from infection [24]. Furthermore, secretory IgA $(\operatorname{sIg} \mathrm{A})$ increased in patients with spondyloarthritis [25]. On the other hand, impaired CD89 expression was responsible for the abnormality of serum IgA. CD89, a specific IgA $\mathrm{FC}_{\mathrm{C}}$ receptor $\left(\mathrm{F}_{\mathbb{}} \mathrm{R}\right)$, is involved in the clearance of IgA and maintenance of serum IgA homeostasis. CD89 expression markedly downregulated in AS patients and was inversely correlated with the IgA serum levels. In conclusion, IgA was overproduced and was less cleared or recycled more in AS patients, leading to hyper-IgA serum levels.

Although elevated IgA and IgA-immune complex levels were commonly observed in AS patients, the role of IgA in AS was controversial. Pathogenesis of IgAN in AS was unclear. However, combined with the fact that renal impairment could happen at any stage of AS, there possibly were some circulating subjects in AS patients that could cause both kidney disease and arthritis, and antibodies or inflammatory factors were the most likely suspects. Recently, a key character came to light to elucidate the pathogenesis in pIgAN, that is, deposits of glycosylation-deficient IgA1 (Gd-IgA1) and its immune complex in the glomerular mesangium. Eventually, a research team from Japan revealed antibodies against Gd-IgA1 were mainly IgG subtype in pIgAN $[26,27]$. Gd-IgA1 and its immune complex were observed in the serum and renal tissue in patients with Henoch-Schönlein purpura nephritis $[28,29]$. Gd-IgA1 and its antibodies possibly existed in the serum and deposited in the glomerular mesangium of IgAN-AS patients, participating in the pathogenesis and development of IgAN-AS; however, further studies are needed to verify and illustrate it.

Few studies reported renal outcomes of AS patients with renal involvement. A recent study conducted by Barbouch et al. [30] observed the renal outcomes of renal amyloidosis in AS, 6 patients (46.1\%) reached ESRD when they were diagnosed as renal amyloidosis, and 3 patients (23.1\%) progressed to ESRD at the end of follow-up. Lee et al. [31] showed a patient with amyloid A amyloidosis secondary to underlying AS achieved complete remission of nephrotic syndrome; however, re-biopsy revealed there was little change pathologically. The literature has rarely mentioned the renal outcomes of secondary IgAN in AS. Marocchi et al. [32] studied a patient with AS and secondary IgAN, which progressed to chronic renal disease and required hemodialysis, in the course of treatment with infliximab. In the present study, renal outcomes either clinical remission or the eGFR change performed well in both the IgAN and non-IgAN subpopulations. No patients progressed to ESRD or eGFR declined $>50 \%$, and eventually only 1 patients had an eGFR decline $>30 \%$.

In this study, a few distinctive pathological features were found between IgAN-AS and pIgAN. The pathological characteristics of IgAN-AS were described in our recently published work [8]. It was likely that patients with IgAN-AS had less E1, S1, T1-2, and necrosis lesions 
than those with pIgAN in the MCAC cohort and the pooled cohort. The M1 lesion occurred comparatively in patients with IgAN-AS and those with pIgAN. In addition, the difference in the incidences of crescent lesions fluctuated depending on the population being compared. The lighter pathological manifestation in patients with AS than pIgAN corrected with the better renal prognosis. Longer follow-up time and multicenter study are needed to re-analyze the renal prognosis and explore the risk factors for renal progression in IgAN-AS. Furthermore, research studies are urgently needed to assess the applicability of the Oxford classification for IgAN in patients with IgAN-AS.

Our study naturally has a few limitations. First, an observational study cannot avoid bias in comparison with randomized controlled trial design. Second, the followup period was comparatively short, and the renal survival and associated risk factors were not analyzed, because it is hard to select a convincing terminal event. Third, this is a single experience of a large tertiary referral center. Future well-designed prospective multicenter studies are urgently needed to testify the risk factors confirmed in our cohort and to explore the effect of conventional treatment to improve the long-term prognosis of IgAN-AS.

In conclusion, our cohort provided a histological spectrum of kidney disease associated with AS, and IgAN was the dominant pathological type (74.2\%). Multivariate binary logistic regression analysis demonstrated that serum $\operatorname{IgA}$ $>3.45 \mathrm{~g} / \mathrm{L}$ and IgG $>9.06 \mathrm{~g} / \mathrm{L}$ were risk factors for the occurrence of IgAN. A few different pathological features were found between IgAN-AS and pIgAN. The renal prognosis of kidney disease in AS was good, appropriately two-thirds of the patients achieved complete remission or partial remission, and eGFR decline $>30 \%$ happened in only 1 patient.

\section{Acknowledgement}

The authors thank the statistical support of Tingyu Chen and acknowledge the editorial assistance of Xiao Huang.

\section{Statement of Ethics}

All procedures performed in studies involving human participants were in accordance with the ethical standards of the institutional and/or national research committee and with the $1964 \mathrm{Hel}-$ sinki declaration and its later amendments or comparable ethical standards. The study was approved by the Research Ethics Committee of JMC-NMU (approval number: 2018NZKYKS-002-01). Due to the retrospective nature of the study, written informed consent for participation in the study was waived.

\section{Conflict of Interest Statement}

The authors have no conflicts of interest to declare.

\section{Funding Sources}

The authors did not receive any funding.

\section{Author Contributions}

Dafeng He and prof. Zheng Tang designed this study. Dafeng $\mathrm{He}$ and Rong Wang took responsibility for the analysis and data interpretation. Shaoshan Liang and Dandan Liang reviewed the analysis and the first draft of the manuscript. Caihong Zeng and Feng $\mathrm{Xu}$ provided pathological support and helped draft the pathology part. Prof. Zheng Tang provided intellectual content of critical importance to the work and approved the final version of the manuscript.

\section{References}

1 Braun J, Sieper J. Ankylosing spondylitis. Lancet. 2007;369:1379-90.

2 Lee SH, Lee EJ, Chung SW, Song R, Moon JY, Lee SH, et al. Renal involvement in ankylosing spondylitis: prevalence, pathology, response to TNF-a blocker. Rheumatol Int. 2013;33(7): 1689-92.

3 Dubash S, McGonagle D, Marzo-Ortega H. New advances in the understanding and treatment of axial spondyloarthritis: from chance to choice. Ther Adv Chronic Dis. 2018;9(3): 77-87.

4 Dougados M, Baeten D. Spondyloarthritis. Lancet. 2011;377:2127-37.

5 Wu Y, Zhang G, Wang N, Xue Q. Risk factors of renal involvement based on different man- ifestations in patients with ankylosing spondylitis. Kidney Blood Press Res. 2018;43(2): 367-77.

6 Pascual J, Teruel JL, Ortuño J. Endstage renal disease in a case of AS and amyloidosis. J Rheumatol. 1992;19(1):183-4.

7 Azevedo DC, Ferreira GA, Carvalho MA. IgA nephropathy in patients with spondyloarthritis followed-up at the Rheumatology Service of Hospital das Clínicas-UFMG. Rev Bras Reumatol. 2011;51(5):417-22.

8 He D, Wang R, Liang S, Liang D, Xu F, Zeng $\mathrm{C}$, et al. Comparison of secondary IgA nephropathy in patients with ankylosing spondylitis and rheumatoid arthritis. Mod Rheumatol. 2019 Nov 22:1-20.
9 Zeng CH, Le W, Ni Z, Zhang M, Miao L, Luo $\mathrm{P}$, et al. A multicenter application and evaluation of the Oxford classification of IgA nephropathy in adult chinese patients. Am J Kidney Dis. 2012 Nov;60(5):812-20.

10 Barbour SJ, Espino-Hernandez G, Reich HN, Coppo R, Roberts IS, Feehally J, et al. The MEST score provides earlier risk prediction in lgA nephropathy. Kidney Int. 2016 Jan;89(1):167-75.

11 Working Group of the International IgA Nephropathy Network and the Renal Pathology Society; Cattran DC, Coppo R, Cook HT, Feehally J, Roberts IS, et al. The Oxford classification of IgA nephropathy: rationale, clinicopathological correlations, and classification. Kidney Int. 2009 Sep;76(5):534-45. 
12 Working Group of the International IgA Nephropathy Network and the Renal Pathology Society; Roberts IS, Cook HT, Troyanov S, Alpers CE, Amore A, et al. The Oxford classification of IgA nephropathy: pathology definitions, correlations, and reproducibility. Kidney Int. 2009 Sep;76(5):546-56.

13 Haas M, Verhave JC, Liu ZH, Alpers CE, Barratt J, Becker JU, et al. A multicenter study of the predictive value of crescents in IgA nephropathy. J Am Soc Nephrol. 2017 Feb; 28(2):691-701.

14 Trimarchi H, Barratt J, Cattran DC, Cook HT, Coppo R, Haas M, et al. Oxford classification of IgA nephropathy 2016: an update from the IgA Nephropathy Classification Working Group. Kidney Int. 2017 May;91(5):1014-21.

15 Ben Taarit C, Ajlani H, Ben Moussa F, Ben Abdallah T, Ben Maïz H, Khedher A. Renal involvement in ankylosing spondylitis: concerning 210 cases. Rev Med Interne. 2005; 26(12):966-9.

16 Hara S, Sakamoto N, Ishimatsu Y, Kakugawa T, Shimada M, Kohno S. Diffuse alveolar hemorrhage in a patient with ankylosing spondylitis. Intern Med. 2013;52(17):1963-6.

17 de Vries M, van der Horst-Bruinsma I, van Hoogstraten I, van Bodegraven A, von Blomberg BM, Ratnawati $\mathrm{H}$, et al. pANCA, ASCA, and $\mathrm{OmpC}$ antibodies in patients with ankylosing spondylitis without inflammatory bowel disease. J Rheumatol. 2010;37(11): $2340-4$.

18 Li S, Liu Z, Chen H, Ge Y, Hu W, Li L. IgA nephropathy associated with ankylosing spondylitis. J Nephrol Dialy Transplant. 2007; 16(3):229-232.
19 Montenegro V, Monteiro RC. Elevation of serum IgA in spondyloarthropathies and IgA nephropathy and its pathogenic role. Curr Opin Rheumatol. 1999;11(4):265-72.

20 Hocini H, Iscaki S, Benlahrache C, Vitalis L, Chevalier X, Larget-Piet B, et al. Increased levels of serum IgA as IgA1 monomers in ankylosing spondylitis. Ann Rheum Dis. 1992; 51(6):790-2.

21 Van Praet L, Van den Bosch FE, Jacques P, Carron P, Jans L, Colman R, et al. Microscopic gut inflammation in axial spondyloarthritis: a multiparametric predictive model. Ann Rheum Dis. 2013;72(3):414-7.

22 Ahn SM, Kim Y-G, Bae S-H, Lim DH, Hong $\mathrm{S}$, Park SH, et al. Ileocolonoscopic findings in patients with ankylosing spondylitis: a single center retrospective study. Korean J Intern Med. 2018;32(9):916-22.

23 Ciccia F, Guggino G, Rizzo A, Alessandro R, Luchetti MM, Milling S, et al. Dysbiosis and zonulin upregulation alter gut epithelial and vascular barriers in patients with ankylosing spondylitis. Ann Rheum Dis. 2017;76(6):1123-32.

24 Yang L, Wang L, Wang X, Xian CJ, Lu H. A possible role of intestinal microbiota in the pathogenesis of ankylosing spondylitis. Int J Mol Sci. 2016;17(12):2126.

25 Salas-Cuestas F, Bautista-Molano W, BelloGualtero JM, Arias I, Castillo DM, ChilaMoreno L, et al. Higher levels of secretory IgA are associated with low disease activity index in patients with reactive arthritis and undifferentiated spondyloarthritis. Front Immunol. 2017;8:476.

26 Placzek WJ, Yanagawa H, Makita Y, Renfrow MB, Julian BA, Rizk DV, et al. Serum galac-
tose-deficient-IgA1 and IgG autoantibodies correlate in patients with IgA nephropathy. PLoS One. 2018;13(1):e0190967.

27 Suzuki Y, Matsuzaki K, Suzuki H, Okazaki K, Yanagawa $\mathrm{H}$, Ieiri N, et al. Serum levels of galactose-deficient immunoglobulin (Ig) Al and related immune complex are associated with disease activity of IgA nephropathy. Clin Exp Nephrol. 2014;18(5):770-7.

28 Suzuki H, Yasutake J, Makita Y, Tanbo Y, Yamasaki K, Sofue T, et al. IgA nephropathy and IgA vasculitis with nephritis have a shared feature involving galactose-deficient IgA1oriented pathogenesis. Kidney Int. 2018; 93(3):700-5.

29 Kiryluk K, Moldoveanu Z, Sanders JT, Eison TM, Suzuki H, Julian BA, et al. Aberrant glycosylation of IgA1 is inherited in both pediatric IgA nephropathy and Henoch-Schonlein purpura nephritis. Kidney Int. 2011;80(1): 79-87.

30 Barbouch S, Hajji M, Jaziri F, Aoudia R, Fellah E, Hedri H, et al. Renal amyloidosis in ankylosing spondylitis: a monocentric study and review of literature. Saudi J Kidney Dis Transpl. 2018;29(2):386-91.

31 Lee YH, Kim EY, Jeong DW, Kim YG, Lee SH, Song R, et al. Complete remission of nephrotic syndrome without resolution of amyloid deposit after anti-tumor necrosis factor alpha therapy in a patient with ankylosing spondylitis. J Clin Rheumatol. 2016;22(2):86-8.

32 Marocchi E, Spadaro A, Giannakakis K, Priori R, Valesini G. Infliximab in a patient with ankylosing spondylitis and secondary IgA nephropathy requiring haemodialysis. Clin Exp Rheumatol. 2010;28(3):440. 